\title{
DEFINING PLAGIARISM: STUDENT AND STAFF PERCEPTIONS OF A GREY CONCEPT
}

\author{
H. Louw \\ Centre for Academic and Professional Language Practice, \\ North-West University, Potchefstroom Campus, \\ Potchefstroom, South Africa \\ e-mail: henk.louw@nwu.ac.za
}

ABSTRACT

The spectacular rise of the Internet and the associated 'copy-paste culture' of generation $Y$ students have brought plagiarism to greater public attention since the late 1990s. Studies reported in numerous academic articles have found that many students commit plagiarism either unwittingly or from lack of skill. This article aims firstly to show that plagiarism is often caused by pedagogical shortcomings due to the difficulty of defining plagiarism accurately. It shows how popular definitions of plagiarism actually overlap with the lower levels of taxonomies of learning and how the concepts of novelty, paraphrasing and application of information are context-sensitive in academia. An attempt is made to define plagiarism anew and a questionnaire that was distributed to 17000 students and 810 staff members at the North-West University is used to identify the different perceptions of students and staff in defining plagiarism.

Keywords: plagiarism definition, perceptions, paraphrasing, Turnitin, academic novelty, academic application, source use, plagiarism prevention

\section{INTRODUCTION}

Many academic institutions try to use the so-called 'honour pledge' to deter students from committing plagiarism. Some authors even suggest that an 'academic honesty course' should be included in students' training (Voelker, Love and Pentina 2011). The honour pledge is also an integrated part of Turnitin (the online plagiarism checker) and many online learning management systems. The implication is that the occurrence of plagiarism is seemingly regarded as an ethical failure, i.e. if plagiarism occurs, the normal academic ethics of hard work, individual effort and recognition of the work of others has failed, leading to a 'cheating culture' in the words of Crittenden, Hanna and Peterson (2009). This article argues that plagiarism is much more than an ethical failure, or even an awareness failure as suggested by Voelker et al. (2011, 41), but rather a pedagogical failure, based in part on the lack of a definition of plagiarism (Sutherland-Smith 2005) and students' inability to translate a vaguely defined theory into practice. The notion that plagiarism is often a lack of skill or inability to apply knowledge 
is not new (see Pecorari 2003), and unintentional plagiarism has even been labelled an attempt at 'academic survival' or simply part of the learning process (Currie 1998). However, the requirements set by taxonomies of learning and by generally used classifications of plagiarism do not necessarily fit with the expectations of avoiding plagiarism. Stated differently, the learning process and the guidelines for learning put students at risk of being accused of plagiarism.

This article deals with plagiarism in two parts. In the first part, the difficulty of defining plagiarism is described in terms of three frequently occurring grey areas: when is something paraphrased, when is something novel, and when is something applied? This is done with reference to situations outside and inside academia, as well as to Bloom's taxonomy of learning (Atherton 2013) and the Structure of Observed Learning Outcomes (SOLO) taxonomy of learning (Atherton 2013). By illustrating how all three of these areas are in fact not clearly defined (or at least are context specific), it is shown that plagiarism is a more nuanced issue than simply a question of failed ethics and even sometimes failed pedagogy. Based on this discussion, a further definition of plagiarism is attempted.

The second part of the article reports on the results of an exploratory questionnaire distributed to students and lecturers to investigate to what extent the students and lecturers are on the same wavelength regarding plagiarism. The results from the questionnaire indicate that the definition from the discussion can hold its own relatively well in an academic context.

\section{PART ONE: WHEN IS SOMETHING PLAGIARISM?}

\section{University definitions of plagiarism}

Most universities have some kind of official statement on plagiarism. Common elements occurring in the numerous university definitions and on sites such as Plagiarism.org include taking credit for or benefitting from somebody else's ideas, words, concepts, formulations, etc. without giving due credit by means of referencing or quoting, and presenting work for personal benefit which does not contain individual authorship (for examples, ${ }^{1}$ see Plagiarism.org 2014; Brown University Writing Centre 2015; Council of Writing Program Administrators 2003; Fishman 2009; North-West University 2013.) Note that the definitions mention nothing about the (much-debated) topic of self-plagiarism, but they do state that the author has to make some contribution and cannot just 'remix' the work of other authors. 


\section{Turnitin versus taxonomies of learning}

The Turnitin white paper on categories of plagiarism (Turnitin 2012) makes provision for 10 kinds of plagiarism in order of severity: clone, Ctrl-C, find-replace, remix, recycle, hybrid, mashup, 404-error, aggregator, re-tweet. Due to space constraints these cannot all be explained in detail.

If one compares the Structure of Observed Learning Outcomes (SOLO) taxonomy of learning to these categories, the Turnitin categories of plagiarism become problematic if they are taken to the letter. In SOLO (Atherton 2013), learning moves through phases from prestructural, to unistructural, to multistructural, to relational, to abstract relational. Up to the multistructural level, students can make connections between information, but miss metaconnections and the significance of the whole. An aggregator piece of work fits this category, as do a mashup, a hybrid and a re-tweet. In other words, the natural process a person follows to acquire new knowledge puts that person in danger of committing plagiarism, especially if the view is taken that students should write to learn, not just to indicate what has been learned. Currie (1998), as mentioned already, also remarks that plagiarism could be considered part of the learning process.

In Bloom's renowned taxonomy of learning (Atherton 2013), the cognitive domain provides for analysis, synthesis and evaluation as the three topmost categories. In these categories one would not expect plagiarism (at least not as defined by the Turnitin white paper); however, in the revised taxonomy (Krathwohl 2002), the topmost category is labelled 'creating'. Immediately a move is made into the area in which old knowledge is used to create new applications in different contexts, something which can be seen as copyright infringement (see the discussion below).

In both of these taxonomies of learning, application is not a big requirement for first-year students. Universities do, however, require students to reference information obtained (even if they do not have to apply it yet) and to paraphrase information. Although this sounds simple enough, for students (and some academics) this is exactly where the first 'grey' area regarding plagiarism occurs in practice. What does 'paraphrase' mean precisely?

\section{Paraphrasing is plagiarism unless referenced}

Almost without fail, students from first-year level right up to $\mathrm{PhD}$ will answer that paraphrasing means to rephrase somebody else's words into one's own words. This definition, although correct as a dictionary definition, is actually plagiarism within the academic context unless it is accompanied by an academic second part of the definition, which should read 'and then 
reference it immediately'. If a person 'rewords' somebody else's idea without referencing it, this is plagiarism from an academic perspective since there is a lack of recognition for the idea of the other person. A lack of correct referencing is considered plagiarism as well, despite the fact that it is not necessarily intentional. Voelker et al. (2011) also found that students unintentionally plagiarise. Many (or even most) university policies on plagiarism refer to referencing as an important aspect of avoiding plagiarism (e.g. University of Illinois at Chicago 2015), although the Turnitin white paper on the different types of plagiarism could still label it as a 're-tweet' - their lowest category of plagiarism (Turnitin 2012).

As a practical example of how this theoretical definition fails to apply in practice, consider this anecdotal situation: In numerous classes and workshops since 2010 (90 and counting), the author did a specific exercise with students from first year to $\mathrm{PhD}$ level. The basic exercise is to ask three or four students for their opinion on a specific topic. The opinion is then displayed on a screen with their surnames and the dates in brackets, and the students are informed that 'Professor Smith (or whatever the name of the student who provided the statement) published this sentence in his book', or 'Dr Brown wrote this in her journal article' or 'Jimmy Jones wrote this in an Internet article'. Colour coding is used to separate the different ideas. The class as a whole is then instructed to paraphrase the information and to integrate it into either one sentence or one paragraph. One answer from a student in the group (student XXX in the figures) is then used as an example. Without fail, what happens is shown in Figure 1.

\begin{tabular}{|l|l|}
\hline Original sentences on the board & Rewritten by student XXX \\
\hline The food in the cafeteria is tasty (Smith 2014). & $\begin{array}{l}\text { Students prefer to buy food in the university cafeteria since } \\
\text { Cafeteria food is unhealthy since it is often deep fried } \\
\text { it saves time, and is convenient and tasty. Unfortunately it is } \\
\text { (Brown 2015). }\end{array}$ \\
$\begin{array}{l}\text { It is time-saving and convenient for students to buy since most of the food is prepared in oil. } \\
\text { food in the cafeteria rather than to make their own } \\
\text { (Jones 2012). }\end{array}$ \\
\hline
\end{tabular}

Figure 1: First draft of paraphrasing activity

The students are then asked: 'If the whole assignment is done in this manner, with information obtained from books, journals and Internet articles and then paraphrased and integrated, what could a student legitimately expect to receive as a mark?' Answers generally range from 55-95 per cent. The students are then informed by the lecturer that in fact student XXX committed plagiarism and would receive a mark of zero and probably be expelled from university since the originators of the ideas are not referenced in the paraphrased version. The concept is usually grasped quickly and students then insert the references. They are then asked again by the lecturer to provide marks estimates. The students usually again estimate marks in the range of 55-85 per cent. The lecturer then informs them that since there is no substantial thought on the part of the student ('OK, but what do YOU think about cafeteria food?' or 'OK, but is this 
applicable to our university's cafeteria?'), the mark cannot really be more than 65 per cent. This is again highlighted in colours, and the contribution by the student is shown in a different colour as in Figure 2.

\begin{tabular}{|l|l|}
\hline Referenced version & Rewritten by student XXX \\
\hline $\begin{array}{l}\text { Students prefer to buy food in the university cafeteria } \\
\text { since it saves time, and is convenient (Jones 2012) } \\
\text { and tasty (Smith 2014). Unfortunately it is unhealthy } \\
\text { since most of the food is prepared in oil (Brown 2015). }\end{array}$ & $\begin{array}{l}\text { Students prefer to buy food in the university cafeteria } \\
\text { since it saves time, and is convenient (Jones 2014) and } \\
\text { tasty (Smith 2014). Unfortunately it is unhealthy since } \\
\text { most of the food is prepared in oil (Brown 2015). This } \\
\text { implies that... }\end{array}$ \\
\hline
\end{tabular}

Figure 2: Second draft of paraphrasing exercise

The implication is that the student has done nothing yet but find and collect information. Turnitin (2012) would label this an 'aggregator' offence, but the 'aggregator' category in Turnitin's plagiarism categories cannot actually be considered plagiarism according to any of the definitions of plagiarism published by universities. Despite most students being warned repeatedly 'not to commit plagiarism', somehow the knowledge that plagiarism should be avoided does not translate into actual actions to be taken to avoid it. This is not a lack of knowledge (they know to avoid plagiarism), but of skill and application (they do not know how).

The question is, since there is no application in Figure 2, can a student expect to earn (high) marks for the information? According to Turnitin, it is an 'aggregator' offence and thus the answer is no, but according to the taxonomies of learning, apparently first-year students can earn marks for this since individual application is not yet such a big requirement for them. An academic definition of paraphrasing should therefore read 'Rephrase somebody else's words or ideas into your own words, and provide a reference to the original author of the idea'. To fit in with the taxonomies of learning mentioned above, one further step at a higher level would then be to apply the information in the current context or to create new information based on the old in order to prove mastery and individual thought, or as Yamada (2003) calls it, 'the role of inferential thinking'.

So a definition of paraphrasing which will avoid plagiarism should then read: 'Rephrase somebody else's words or ideas into your own words, providing a reference and applying the information to a specific context'. But even this is contentious since there are two more grey areas regarding plagiarism.

\section{When is something novel?}

The second grey area regarding the definition of plagiarism stems from the issue of what exactly constitutes a 'stolen idea'. In other words, when is something 'novel'? Many movie plots and 
songs are very similar in nature, with small differences in contexts. For example, major similarities between the two films Pocahontas and Avatar, (reproduced in Figure 3 from themovieblog.com (Anonymous 2010)) were not considered plagiarism, although it may well be argued that the 'idea' in Avatar is so similar to that in Pocahontas, and so lacking in novelty that it could (should?) be considered plagiarism - it is after all, simply the same story in a different context. It actually fits exceptionally well with the Turnitin term 'find-replace' which is their third highest offence. Of course, no movie will screen credits saying 'adapted from Steven Spielberg's Saving Private Ryan' or something similar, whereas no article will appear without a reference and bibliography. How is that much different from using an idea from an academic article and applying it to a new case? Or, for that matter, using a model in economics and applying it to a different country?

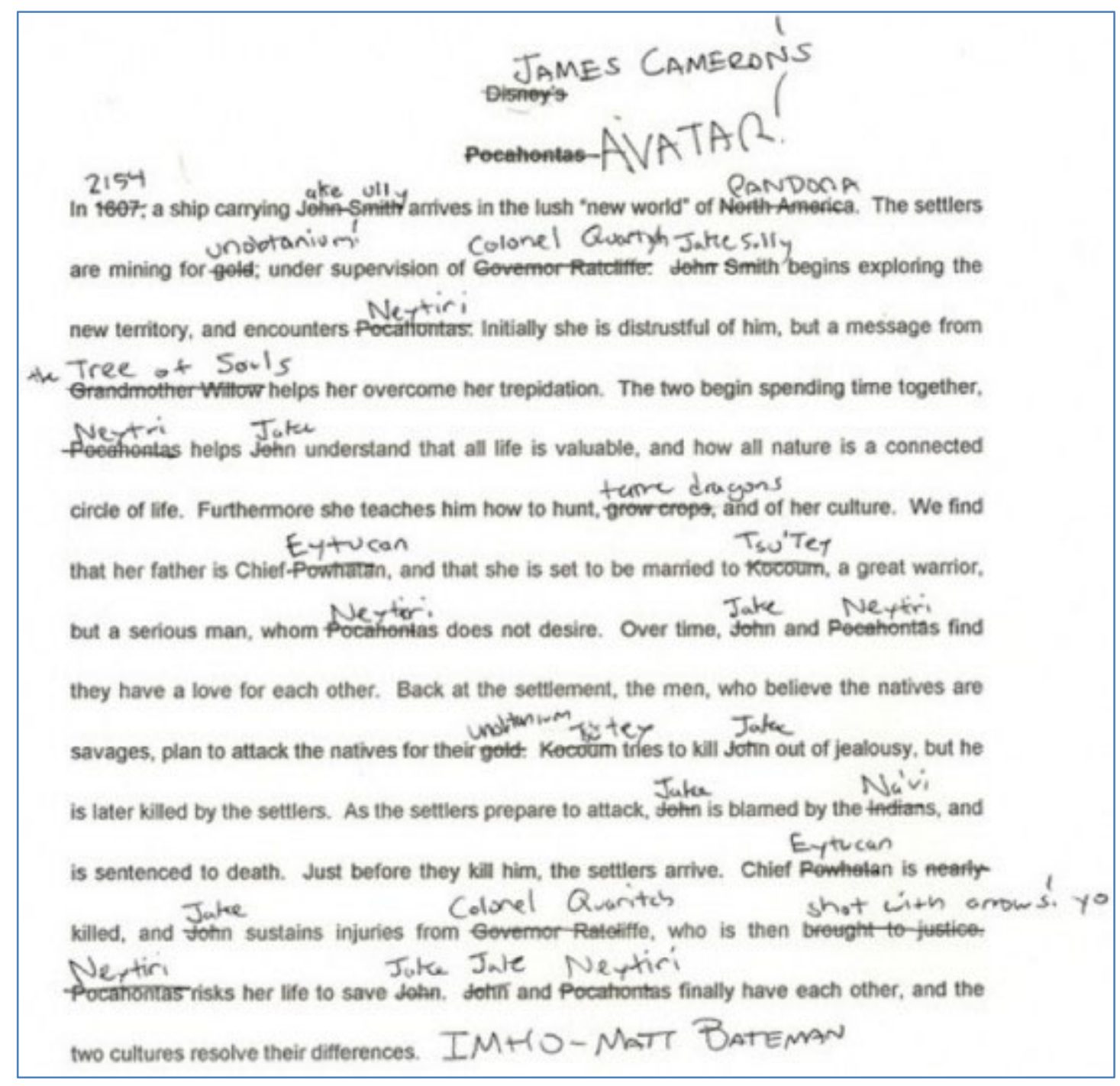

Figure 3: Avatar is Pocahontas in Space 
A similar situation from the creative arts, which turned out differently, was the controversial music single Blurred Lines by Robin Thicke and Pharrel Williams, which was seen as so similar to the earlier Got to give it up by Marvin Gaye, that a US court ruled it to be copyright infringement and damages had to be paid (Grow 2015). What makes this interesting is that Williams freely admitted that Gaye's song was the inspiration for Blurred Lines. The artist would obviously not have made the statement if he expected to be sued for copyright infringement. This begs the question: when is something novel enough to be 'inspired by' instead of seen as copyright infringement? To rephrase the question in the academic context: When may an academic or student find insight into a new concept by reading non-related material, or as stated above, when may a model used in one context be repackaged to be used in a different context? The simple answer seems to be 'any time, as long as you reference it', but Turnitin may then still label it as an 'aggregator'. It therefore seems that substantial individual contribution (application) should be added in any situation to avoid the accusation of plagiarism, but what substantial means is open to interpretation.

\section{When is it plagiarism and when is it application within context?}

Another issue contributing to general student confusion regarding what plagiarism is, stems from a misapprehension of what plagiarism detection software actually does. Turnitin and similar systems are not plagiarism detection software - they are similarity detection software. A similarity is not necessarily an act of plagiarism if referenced correctly. In the same vein, a stolen idea, worded differently, is not picked up by software like Turnitin. (Turnitin would not have seen similarities between the two songs or the two movies mentioned above, for example). Turnitin is also not able to identify texts which have been processed through software such as Google Translate or one of the many 'paraphrasing services' (such as paraphrasing-tool.com) on the Internet. Students with some knowledge of its workings and with some computer ability, will find ways around software such as Turnitin and can turn in papers devoid of any similarities (or at least in the similarity index number range deemed safe by their lecturers), but all the information in those non-similar papers can still come from other sources. In other words, stolen ideas presented in a way that Turnitin cannot detect, will ensure a student better marks, even if the student does not necessarily understand the work. Therefore, students can present (share) information but not necessarily apply it. The question is whether a student who can find information is able to use it. Obviously 'finding information' is not the same as 'being able to use information' or 'understanding information'.

There are still academics and students who sincerely believe that Turnitin is a plagiarism 
checker, and this misconception leads to ineffective pedagogy, witch hunts and administrative difficulties. There are many anecdotal examples available to back this up. In more than one instance, the author was asked for his 'professional opinion' by senior students or a university disciplinary office. In one (not unique) case, a student was reported to the university disciplinary office for obtaining a high similarity index in Turnitin. However, every single bit of information in the text was referenced correctly. In this case, it was not plagiarism since the author definitely did not attempt to present somebody else's ideas as her own. It was simply a case of poor pedagogy since the student was under the impression that a lack of any substantial, individual application would constitute something on which academic advancement could be made. Turnitin labels this a 'mashup', but the question remains as to what extent a first-year student is required to apply information.

A second anecdotal example is a situation in which a postgraduate student explained a specific theoretical model at length in order to be able to apply the model to a completely novel situation - a new application of the model (this frequently occurs in postgraduate studies in economics). One of the examiners reported the student for plagiarism. The exasperated student wanted to know how a fully referenced and paraphrased model could be plagiarism, while the examiner obviously felt that the student was trying to benefit from the work of others. This seems to be a case of varying interpretations, with the student and the study leader working from a different viewpoint as the examiner regarding the extent to which prior work may be included in new academic material.

A third example of where the similarity index scores frequently fail to identify plagiarism is in legal texts. A law may not be paraphrased; it can only be interpreted but if it is used in an argument it has to be quoted verbatim. A postgraduate student in tax law, for example, will write a 500-word tax advice note in which 300 of the 500 words simply quote the law and the last 200 words are the interpretation and advice to the client. From a similarity index point of view, 60 per cent of the text is an issue, while from a tax advisor's point of view, choosing the right law to quote is paramount (worthy of earning academic advancement) and the 200-word interpretation is in turn worthy of earning marks, but only if the right law was quoted in the first place.

The discussion on the grey definition of plagiarism can continue at length, and each academic institution that takes plagiarism seriously should strive to define what they mean by the term plagiarism. To summarise this section: the definition of the term plagiarism is a grey definition, since it should be seen in the context of the requirements set by taxonomies of learning, paraphrasing is not similar to understanding, the concept of 'novelty' in academic 
situations is in itself difficult to quantify, and different contexts within academic situations require different interpretations of what is meant by application (once again keeping in mind the taxonomies of learning). For something not to be considered plagiarism, it has to be so novel that there are no similarities whatsoever (and this is not really feasible depending on context and keeping the norms of academia in mind), or it has to be referenced consistently as well as applied to a new context to the extent that substantial individual work can be identified or to the extent that student cognition of the topic can be identified.

\section{PART TWO: STUDENT AND LECTURER PERCEPTIONS OF PLAGIARISM}

Having established that plagiarism itself is a difficult concept to define, the question now is whether students and lecturers see it in the same way. To establish what students and staff see as plagiarism and whether the definitions corresponds, an exploratory study was conducted by distributing a questionnaire on the Potchefstroom Campus of the North-West University. The questionnaire was set up electronically in FluidSurveys and links were sent to the e-mail addresses of all the academic staff and all the students on campus. The responses were collected anonymously, although some biographic information such as year group and field of study were recorded, and resulted in convenience samples of $n=111$ for the academic staff and $n=2414$ for the students.

Since no constructs were tested in the questionnaire, construct validity is not applicable. The questionnaire was developed in collaboration with Statistical Consultation Services on campus to ensure face validity. The questions were also checked by the disciplinary office, staff at the university writing laboratory and lecturers in the faculty of Arts to ensure content validity. The questionnaire entailed more than 40 questions, mostly Likert scale, with some open response questions, and it gathered information on a number of areas related to plagiarism. This article reports only on the questions related to defining plagiarism.

\section{FINDINGS AND DISCUSSION}

\section{Plagiarism is not identified consistently by lecturers and markers}

\section{Awareness of identification techniques}

It seems that most respondents are aware of the general techniques to identify plagiarism. The methods mostly used by lecturers to identify plagiarism are shown in Table 1. 
Table 1: Techniques used by lecturers to identify plagiarism

\begin{tabular}{|l|l|l|}
\hline Response & Percentage & Count \\
\hline Differences in language use & 85 & 97 \\
\hline Differences in language style & 82 & 93 \\
\hline Formatting differences & 71 & 81 \\
\hline 'Gut feeling' & 70 & 80 \\
\hline Notice a shortage of references in the text & 67 & 76 \\
\hline $\begin{array}{l}\text { Notice a discrepancy between references in the text and entries in the } \\
\text { bibliography }\end{array}$ & 59 & 67 \\
\hline Notice an absence of bibliography or incorrect bibliography & 59 & 67 \\
\hline Turnitin & 53 & 59 \\
\hline Google search & 52 & 11 \\
\hline Other: Please specify & 10 & $\mathbf{1 1 4}$ \\
\hline Total responses & & \\
\hline
\end{tabular}

Some lecturers also indicated they simply knew the source material well enough to recognise plagiarism, recognise similarities between the work of different students and notice when students have irrelevant information in the text. Students who copy verbatim from Wikipedia for example, will often have completely irrelevant information in their texts (mostly in their introductions).

Two interesting implications arise from this information: Firstly, Turnitin is used less frequently than it could be despite its shortcomings. There are various reasons for this, but they will not be discussed here due to space constraints. Secondly, the two top methods for identifying plagiarism have to do with students' inability or unwillingness to write information in their own words. In the open response section to this question, lecturers also indicated that poor translations of English texts into Afrikaans (another student inability) are clues to plagiarism. To emphasise: this is a lack of skill (application), not knowledge.

\section{Lecturer consensus regarding a working definition of plagiarism on campus}

It seems that most lecturers agree in principle on what constitutes plagiarism when one is dealing with obvious, direct plagiarism such as direct copying - 98 per cent of the respondents viewed this as plagiarism. Problems creep in with nuances in the definition:

1. Sixty-seven per cent of the respondents found it to be plagiarism if a student copies verbatim but provides a reference. This is generally not plagiarism but an instance of poor academic conduct and is often a reason for the misinterpretation of Turnitin results.

2. Eighty-five per cent of the respondents found it to be plagiarism if a student purchases an assignment from the Internet. One would expect this number to be 100 per cent, since 
purchased assignments are obviously blatant attempts at passing the work of another off as their own so the number should have been 100 per cent.

3. Seventy-four per cent regarded it as plagiarism if students work together illicitly on an assignment. While group assignments are without doubt encouraged, it is troubling that almost a quarter of the lecturers did not see illicit collaboration as plagiarism. It is possible, though, that lecturers consider this to be a different kind or degree of offence.

4. Only 58 per cent of the respondents considered it as plagiarism if a student submits an assignment without a bibliography, and only 57 per cent considered it plagiarism if a bibliography is present but without citations in the text. The problem with these views is that they tolerate students to 'include' references in a text which are actually simply an indication that they copied pieces of text directly from a source.

5. Some respondents' comments indicated that lecturers will judge something to be plagiarism based on the year level of the student. While this no doubt has a pedagogical intent, the end result is that there is not consistency across year groups or between lecturers, which implies poor pedagogy rather than the intended accommodating pedagogy.

Part of the problem with the identification of plagiarism is that only 60 per cent of the respondents were aware that NWU has official information pamphlets about plagiarism which are distributed on campus, and only 19 per cent indicated they had read the pamphlets thoroughly.

It is therefore necessary to communicate to lecturers a more exact definition with examples as to what entails plagiarism and what might be clues as to when plagiarism had been committed intentionally or unintentionally by students.

\section{(In)Consistency within references and bibliographies}

One of the areas where students may commit plagiarism wittingly or unwittingly is in incorrect, inconsistent or incomplete references and bibliographies. While it is true that a lack of references cited in the text does not necessarily point to plagiarism, it is also true that it opens the gate for intentional or unintentional plagiarism if the sources of information are not indicated as and when they are used in texts.

Only three per cent of the responding lecturers indicated they did not check references cited in the text. Some respondents (52\%) would mark references and bibliographies in detail, while 42 per cent indicated they checked it superficially. Despite indicating that they checked references and bibliographies, only 58 per cent of lecturers said that an assignment without a 
bibliography was considered plagiarism, and only 57 per cent considered a lack of references in the text as plagiarism if a bibliography was present. Most of the respondents (91\%) indicated they checked for references in the text.

Despite the fact that the respondents claimed to mark references and bibliographies, lecturers still regularly find incorrect bibliographical entries as indicated in Table 2, and 51 per cent of students claimed that their lecturers marked their in-text references less than half the time. Incorrect bibliographical entries such as ‘Google.com’ were also reportedly marked as correct according to students. (Note that this question asked participants to 'pick all that apply' so the percentages do not add up to $100 \%$.)

Table 2: Incorrect inscriptions in bibliographies

\begin{tabular}{|l|l|l|}
\hline Response & Percentage & Count \\
\hline Just a URL: http://www.ssisa.com & 83 & 94 \\
\hline Entries such as: 'class notes' or 'study guide' or the lecturer's name & 70 & 79 \\
\hline Search engine's name, e.g. www.google.com or Google Scholar & 68 & 77 \\
\hline Repository of information, e.g.: 'Internet' & 58 & 65 \\
\hline Entries such as ‘General knowledge' & 24 & 27 \\
\hline Other (specify) & 13 & 15 \\
\hline Total responses & & $\mathbf{1 1 3}$ \\
\hline
\end{tabular}

Almost all the lecturers (97\%) claimed that they remind students about plagiarism in class, and 54 per cent claimed to provide examples of plagiarism in class. While these figures are a reason to be pleased rather than alarmed; they should be seen in the light of the already mentioned lack of a universal definition. Experience of the disciplinary office has shown that some of these 'examples' are actually misinformation. 14 per cent of the lecturers felt that it was not their job to teach or warn students about plagiarism, which may indicate a misconception of the effects plagiarism has on long-term student cognition and performance.

\section{Students' awareness of plagiarism}

A number of questions in the questionnaire to students tested their knowledge of what constitutes plagiarism. Table 3 illustrates student knowledge, tested by eliciting true/false responses on several statements related to plagiarism and copyright infringement.

Although item 2 is technically true, one would hope students are required to do more when doing assignments, and move to the application of information instead as discussed above. Item 3 shows a discrepancy with the information obtained from the lecturer questionnaire: if almost 40 per cent of the responding students consider an assignment without a bibliography to be free 
Table 3: Student perceptions of plagiarism

\begin{tabular}{|c|c|c|c|c|}
\hline $\begin{array}{c}\text { Item } \\
\text { number }\end{array}$ & & True & False & $\begin{array}{l}\text { Total } \\
\text { responses }\end{array}$ \\
\hline 1 & $\begin{array}{l}\text { It is plagiarism to copy information directly from a source (such } \\
\text { as a book or from the Internet) without citing references }\end{array}$ & $\begin{array}{l}2970 \\
(98.7 \%)\end{array}$ & $\begin{array}{l}38 \\
(1.3 \%)\end{array}$ & 2908 \\
\hline 2 & $\begin{array}{l}\text { I can copy my entire paper piece by piece from different } \\
\text { sources, as long as I provide references }\end{array}$ & $\begin{array}{l}748 \\
(25.8 \%)\end{array}$ & $\begin{array}{l}2155 \\
(74.2 \%)\end{array}$ & 2903 \\
\hline 3 & $\begin{array}{l}\text { If a paper has no reference list, that paper probably contains } \\
\text { plagiarism }\end{array}$ & $\begin{array}{l}1777 \\
(61.3 \%)\end{array}$ & $\begin{array}{l}1123 \\
(38.7 \%)\end{array}$ & 2900 \\
\hline 4 & $\begin{array}{l}\text { If a paper has a reference list but no in-text references it is } \\
\text { usually an indication of plagiarism }\end{array}$ & $\begin{array}{l}1691 \\
(58.4 \%) \\
\end{array}$ & $\begin{array}{l}1205 \\
(41.6 \%) \\
\end{array}$ & 2896 \\
\hline 5 & $\begin{array}{l}\text { It is plagiarism to buy a paper somewhere and submit it as if it } \\
\text { is mine or to pay somebody to do my paper for me }\end{array}$ & $\begin{array}{l}2785 \\
(96.2 \%)\end{array}$ & $\begin{array}{l}109 \\
(3.8 \%)\end{array}$ & 2894 \\
\hline 6 & $\begin{array}{l}\text { It is plagiarism if two students collaborate on an assignment } \\
\text { that is not group work, and then submit the same assignment } \\
\text { under two different names }\end{array}$ & $\begin{array}{l}2675 \\
(92.4 \%)\end{array}$ & $\begin{array}{l}221 \\
(7.6 \%)\end{array}$ & 2896 \\
\hline 7 & $\begin{array}{l}\text { It is plagiarism if my parents do my assignment (or parts } \\
\text { thereof) for me }\end{array}$ & $\begin{array}{l}2279 \\
(78.7 \%)\end{array}$ & $\begin{array}{l}615 \\
(21.3 \%)\end{array}$ & 2894 \\
\hline 8 & $\begin{array}{l}\text { It is plagiarism to download a photo or an image from the } \\
\text { Internet and to use it in my paper without a reference }\end{array}$ & $\begin{array}{l}2156 \\
(74.6 \%)\end{array}$ & $\begin{array}{l}735 \\
(25.4 \%) \\
\end{array}$ & 2891 \\
\hline 9 & $\begin{array}{l}\text { If I read information in a source and rewrite it in my own } \\
\text { words, I don't need to cite sources, because I used my own } \\
\text { words. }\end{array}$ & $\begin{array}{l}633 \\
(21.9 \%)\end{array}$ & $\begin{array}{l}2257 \\
(78.1 \%)\end{array}$ & 2890 \\
\hline 10 & $\begin{array}{l}\text { If I remember information from class or my textbook and } \\
\text { therefore have it as 'general knowledge' in my head, I do not } \\
\text { need to give a reference if I write it in my own words. }\end{array}$ & $\begin{array}{l}1511 \\
(52.4 \%)\end{array}$ & $\begin{array}{l}1375 \\
(47.6 \%)\end{array}$ & 2886 \\
\hline 11 & $\begin{array}{l}\text { If I copy something from the Internet or a book, but replace } \\
\text { certain words with my own synonyms, I do not need to give a } \\
\text { reference }\end{array}$ & $\begin{array}{l}284 \\
(9.8 \%)\end{array}$ & $\begin{array}{l}2600 \\
(90.2 \%)\end{array}$ & 2884 \\
\hline 12 & $\begin{array}{l}\text { If I translate information on my own or with Google Translate, } \\
\text { it is no longer the original source which means that I do not } \\
\text { need to give a reference }\end{array}$ & $\begin{array}{l}214 \\
(7.4 \%)\end{array}$ & $\begin{array}{l}2671 \\
(92.6 \%)\end{array}$ & 2885 \\
\hline
\end{tabular}

from plagiarism, it may indicate that they are not required to submit bibliographies and/or are unaware that an unreferenced fact from a source is plagiarism. If read in combination with statement 4, it indicates that students are unaware of the interrelation between bibliographies and in-text references - something which personal experience attests to be true.

As is seen in statement number 7, 21.3 per cent of the students did not consider it plagiarism if their parents did their work or parts of it for them. In question 35, 40 per cent of the students indicated that their parents assisted them with work at school, although 73 per cent indicated that their family only gave input and they still had to do the work themselves. Only 4 per cent admitted that their family members sometimes did whole assignments for them. Thirtytwo per cent of students also admitted to receiving assistance from friends at school. At university, the figures change to only 16 per cent receiving assistance from parents and only 1.3 per cent admitting that parents sometimes did whole assignments for them.

Almost 22 per cent of the students also thought that paraphrased information without references is not plagiarism (in keeping with the workshop experiences explained above), and more than half of the student respondents felt that 'general knowledge' of a subject did not need references. Despite these answers, the students did seem to be aware that translations or paraphrasing using synonyms is plagiarism unless referenced. 
(As a note aside: The question on which Table 3 is based was also distributed to 2943 'raw' first-year students during their first-year orientation week. The results differ to the extent that one has to assume that students do learn from compulsory subjects and academic assimilation regarding plagiarism to some extent. However, the lack of space does not permit a full discussion here.)

A follow-up question tested the students' use of secondary sources in a scenario question. In this instance, 62 per cent of the respondents considered it correct to include secondary sources as if the student had read them, but then only to include the primary source in the bibliography. Although 70 per cent of the students knew that they were supposed to find and read the original texts, and 91 per cent knew they could provide a secondary reference, more than 60 per cent of them recommended that the author simply copy the bibliographical entries from the primary source. It seems therefore that if lecturer feedback indicates that a secondary reference is not desirable, students will correct the issue simply by copying the bibliographical entries from their primary source as if they had read the original sources. This points to a misconception regarding the use and reliability of secondary sources and possibly to a lack of feedback when such errors occur. From a practical perspective though, the question should be asked if it is realistic to expect students to read every single article referenced in their primary sources. Or restated, if lecturers expect students to use only primary sources without allowing secondary references, they force students to reference articles which they have not in fact read, and, as one reviewer of this article pointed out, 'no article should be referenced if it has not been read'.

The students also indicated that incorrect bibliographical entries do occur. They identified some incorrect bibliographical entries such as search engine names (35\%) or article repositories such as Ebsco (24\%), the inscription 'class notes’ or only website addresses (69\%) as having occurred in their bibliographies. (This question also asked the respondents to 'pick all that apply', so the percentages do not add up to 100\%). The fact that these figures are so high indicates that despite these errors, student assignments are still accepted and the weights assigned to bibliographies are not heavy enough to deter inaccuracies. The students also indicated that the examples above were marked as correct by lecturers or markers, although 39 per cent of the students claimed that their bibliographies were not marked in detail.

When asked how often references in the text were marked by lecturers or markers, the responses in Table 4 were given.

Although there is an even spread across the spectrum, the results indicate that there are still too many lecturers and markers who ignore referencing, which supports the conjecture that 
Table 4: How frequently are references in the text marked?

\begin{tabular}{|l|l|c|}
\hline Response & Percentage & Count \\
\hline $20-25 \%$ & 33 & 878 \\
\hline $26-50 \%$ & 18 & 478 \\
\hline $51-75 \%$ & 20 & 540 \\
\hline $76-100 \%$ & 29 & 760 \\
\hline Total response & & $\mathbf{2 6 5 6}$ \\
\hline
\end{tabular}

the lecturer questionnaire was filled out by lecturers with an interest in preventing plagiarism. Only 4 per cent of the students indicated that lecturers refuse to mark texts in which the referencing is incorrect. With the serious consequences of plagiarism, it is inconceivable that any lecturer should accept assignments without correct referencing and bibliographies. While it would be overly strict of lecturers to refuse marking assignments in which small technical errors occur in referencing (such as the use of a style different from the prescribed one), lecturers should in fact refuse to mark assignments in which the referencing displays a disregard for any referencing conventions. Examples of this would be when students simply write 'Google' in their bibliography, if there are only in-text references and no bibliography (or vice versa) or if there are discrepancies between the sources cited in the text and those listed in the reference list.

When asked if lecturers discuss plagiarism in class, 5 per cent of the students said their lecturers never talked about it, 36 per cent said only some of their lecturers discussed it and 52 per cent said some of their lecturers provided examples. In the comments section the students frequently indicated that 'all the lecturers' talked about plagiarism, while others indicated that a stern warning at the start of the year was the only information they received. This probably depends on the year group and the subject.

The students also indicated that the knowledge they obtained about plagiarism came from a variety of sources, the top five being Academic Literacy (a compulsory subject for all firstyear students) (69\%), high school teachers (47\%), lecturers other than Academic Literacy lecturers (45\%), all lecturers (38\%) and senior students (32\%). When asked to identify whose responsibility it is to teach students about plagiarism, the responses indicated that it is the responsibility of all academic staff (40\%), Academic Literacy (21\%), students' own responsibility (19\%) and high school (15\%).

\section{Lack of lecturer expectations?}

Lecturers expect students to use quality sources. Lecturers reported they do expect students to have bibliographies and referencing in their assignments about 74 per cent of the time, although 
there are discrepancies between the students' responses and the lecturers' responses to this question. The students indicated that some of their lecturers allow assignments to be handed in without bibliographies and references. (It can be conjectured that for some practical assignments, no referencing or bibliographies are necessary, but these should be a definite minority.) It can therefore not be said that instances of plagiarism occur due to a lack of lecturer expectations. However, as mentioned above, the students also indicated that their bibliographies were not consistently marked and that some incorrect references and bibliographies were marked as correct. Lecturers also expect students to know that they should use reliable sources, and the data indicate that students are aware of the reliability of different kinds of sources.

\section{Lack of skills or malicious intent?}

Although some comments on the questionnaire indicated that some students will commit plagiarism because they do not expect to be caught out, this may be more a case of conjecture since few students indicated that they were aware of actual intentional plagiarism.

Students were asked why they thought students would knowingly commit plagiarism. Table 5 shows the results. (Once again, the students were asked to select all the answers that apply so the percentages do not add up to $100 \%$.) Note that the top four have to do with a lack of ability rather than a lack of intention.

Table 5: Why do students knowingly commit plagiarism?

\begin{tabular}{|l|l|l|}
\hline Response & Percentage & Count \\
\hline They don't know how to do an assignment & 73 & 1940 \\
\hline They don't have time to do an assignment & 72 & 1892 \\
\hline $\begin{array}{l}\text { They have a hard time understanding the meaning of the original source and therefore } \\
\text { prefer to copy instead of using their own words }\end{array}$ & 66 & 1748 \\
\hline $\begin{array}{l}\text { They cannot state the information better in their own words and therefore prefer to } \\
\text { copy it }\end{array}$ & 64 & 1696 \\
\hline $\begin{array}{l}\text { They are not interested in the assignment or the subject and just want to finish the } \\
\text { work as quickly as possible }\end{array}$ & 62 & 1637 \\
\hline They want better marks and don't want to take the chance of doing their own word & 58 & 1528 \\
\hline They don't understand what the lecturer wanted and thus write what their friends write & 51 & 1335 \\
\hline They have failed the subject before and want to get better marks this time & 44 & 1165 \\
\hline They are under pressure from their family or other people to get good marks & 36 & 939 \\
\hline They feel that their parents of friends can do the work better than they can & 25 & 647 \\
\hline Other? Please specify & 4 & 106 \\
\hline Total responses & & 2644 \\
\hline
\end{tabular}

In the open response section to the question on why students commit plagiarism, reasons mostly included laziness, time pressure, an inability to translate from English, or an inability or lack of confidence to paraphrase. The latter two of course again highlight the issue of skill. This clearly matches the findings of Currie (1998) and Pecorari (2003). Currie (1998) states that 'copying 
reflects less an intentional violation of a cultural code than a survival measure in the face of perceived difficulties or deficiencies'. This seems to be the case here as well. Currie also raises the important issue that students' vocabulary is often not sufficient to paraphrase effectively, and research by Nizonkiza, Van Dyk and Louw (2013) supports this - on average student vocabulary levels do not fall within the word bands prescribed in academic word lists.

When asked how often students understand enough of their work to form their own view and write information in their own words, the results indicate that students admit to experiencing problems. Less than half (48\%) of students claim they only understand the work well enough 51-75 per cent of the time, with only 39 per cent indicating 76-100 per cent of the time. Thirteen per cent of the students understand the work less than 50 per cent of the time.

\section{How often does plagiarism occur on campus?}

Twenty-one per cent of the lecturers said they find plagiarism in many of their students' work, while 15 per cent said it is only some students who repeatedly plagiarise. The majority of the lecturers (51\%) find plagiarism in isolated cases only and do not experience it as a big issue.

The plagiarism that does occur is mostly of the copy-and-paste type from the Internet (79\% of lecturers have experienced this), and 68 per cent of the lecturers found direct quotes without references. Sixty-nine per cent indicated that they often find that a few words are changed in quotes, but it remains a basic direct quote. From the student perspective, 53 per cent indicated that they did not know of any students who had committed plagiarism. One can assume that the other 47 per cent were aware of such instances.

\section{RECOMMENDATIONS}

Based on the above findings, a few recommendations can be made.

Firstly, it seems that a standardised definition for plagiarism is needed at university, as well as guidance to lecturers on how to identify plagiarism. Lecturers and marking assistants should receive training in the abilities, use and interpretation of Turnitin.

Students seem to be relatively well informed about plagiarism and its consequences despite the apparent inefficiency of plagiarism information pamphlets. However, it is still recommended that lecturers place a greater emphasis on the presence and correctness of in-text references and bibliographies. It is recommended that assignments not be accepted or marked if there are incorrect or incomplete references and bibliographies, and that the honesty pledge be a set requirement for all subjects and all assignments. In the same way that typed assignments are a minimum requirement for assignments to be accepted, plagiarism-preventive measures 
(such as complete references and bibliographies) should also be applied.

Students may also benefit from being made aware of actual prosecutions for plagiarism as so many of them are unaware of any prosecutions for plagiarism. This may encourage students to seek help, but the focus should always be on 'proactive teaching' (Pecorari 2003) rather than treating the identification of plagiarism as a witch hunt. Awareness should be raised of support structures to assist in understanding work and doing assignments. These support structures are already in place with senior students acting as demonstrators or supplemental instruction facilitators. The university Writing Laboratory is also available. The support structures may assist students to understand the work which will empower them to paraphrase, reference and apply the work more effectively and consistently.

\section{CONCLUSION}

This article proposes that for something not to be considered plagiarism, the information has to be referenced at the very least, but also applied to a new context to the extent that substantial individual contribution and cognition can be identified. However, plagiarism is a multifaceted problem, and defining exactly what constitutes plagiarism is not a straightforward matter. It was argued that within the academic context, there are discrepancies between what Turnitin (as prototypical similarity detection software) defines as plagiarism and the requirements set by taxonomies of learning. Areas of difficulty include how to clarify when an idea is a novel one, what exactly is meant with paraphrasing and when is application or interpretation of information enough to warrant judging it as substantial individual contribution. What this implies is that even with a more nuanced definition, the concept of plagiarism will still remain a grey one at best. Despite this cautionary note, data from the exploratory study revealed that students and staff had relatively similar definitions of plagiarism. Tested against the definition of plagiarism that the discussion in this text arrived at, though, it is troubling that some lecturers allow students to submit work without correct references and bibliographies.

The results from the questionnaire also substantiate that the three-part definition of plagiarism is in line with what is expected of students, keeping in mind the lower levels of the SOLO and Bloom's taxonomies of learning. Since responses from both the students and lecturers indicated that the major cause of plagiarism is mostly a lack of cognition and skill on the part of students, it seems that focused, repeated education and assistance should be applied to combat plagiarism, rather than simply providing information on the consequences of plagiarism. 


\section{ACKNOWLEDGEMENTS}

The author wishes to thank Me. Erika Fourie at the Statistical Consultation Services for assistance with the questionnaires. Two anonymous reviewers are also thanked for their input on a first submission of this article.

\section{ENDNOTE}

1. It is an ironic situation for the context of this article that it is impossible to read or reference all the plagiarism statements of the many universities in the world. The summary by Fishman (2009) seems to be a decent attempt at conglomerating the available material into a general definition. A second irony is that precious few of the university websites with information on plagiarism actually mention where that information comes from.

\section{REFERENCES}

Anonymous. 2010. Avatar really just Pocahontas? 10 January. http://themovieblog.com/2010/avatarreally-just-pocahontas/ (accessed 6 May 2015).

Atherton, J. S. 2013. Learning and teaching; Bloom's taxonomy. http://www.learningandteaching.info/ learning/bloomtax.htm (accessed 22 April 2014).

Atherton, James S. 2013. Learning and teaching; SOLO taxonomy. http://www.learningandteaching. info/learning/solo.htm (accessed 22 April 2014).

Brown University Writing Centre. 2015. What is plagiarism? http://library.brown.edu/libweb/ plagiarism.php (accessed 3 May 2015).

Council of Writing Program Administrators. 2003. Defining and avoiding plagiarism: The WPA statement on best practices. January. http://www.princeton.edu/writing/university/resources/ WPAPlagiarism.pdf (accessed 2 May 2015).

Crittenden, Victoria L., Richard C. Hanna and Robert A. Peterson. 2009. 'The cheating culture: A global societal phenomenon.’ Business Horizons 52: 337-346.

Currie, Pat. 1998. 'Staying out of troble: Apparent plagiarism and academic survival.' Journal of Second Language Writing 7(1): 1-18.

Fishman, Teddi. 2009. “"We know it when we see it” is not good enough: Toward a standard definition of plagiarism that transcends theft, fraud, and copyright.' 4th Asia Pacific Conference on Educational Integrity. University of Wollongong NSW Australia: 1-5.

Grow, Kory. 2015. Robin Thicke, Pharrell lose multi-million dollar 'Blurred lines' lawsuit. 10 March. Anonymous. 2010. Avatar really just Pocahontas? 10 January. http://themovieblog.com/ 2010/avatar-really-just-pocahontas/ (accessed 6 May 2015).

Krathwohl, David R. 2002. 'A revision of Bloom's Taxonomy: An overview.' Theory into practice 41(4): 212-264.

Nizonkiza, Deogratias, Tobie van Dyk and Henk Louw. 2013. 'First-year university students' productive knowledge of collocations.' Stellenbosch Papers in Linguistics Plus 42: 165-181.

North-West University. 2013. 'Don't gamble with your future - plagiarism constitutes academic misconduct.' North-West University.

Pecorari, Diane. 2003. 'Good and original: Plagiarism and patchwriting.' Journal of Second Language Writing 12: 317-345.

Plagiarism.org. 2014. What is plagiarism? http://www.plagiarism.org/plagiarism-101/what-isplagiarism (accessed 3 May 2015).

Sutherland-Smith, Wendy. 2005. 'Pandora's box: Academic perceptions of student plagiarism in 
writing.' Journal of English for Academic Purposes 4: 83-95.

Turnitin. 2012. The plagiarism spectrum - Instructor insights into the 10 types of plagiarism. White Paper, Oakland: iParadigms, LLC.

University of Illionois at Chicago. 2015. THE REALITY AND SOLUTION OF COLLEGE PLAGIARISM INFOGRAPHIC. $\quad \mathrm{http} / / /$ healthinformatics.uic.edu/resources/infographics/the-reality-andsolution-of-college-plagiarism-infographic/ (accessed 30 April 2015).

Voelker, Troy A., Leonard G. Love and Iryna Pentina. 2011. 'Plagiarism: What don't they know?' Journal of Education for Business 87(1): 36-41.

Yamada, K. 2003. What prevents ESL/EFL writers from avoiding plagiarism? Analyses of 10 NorthAmerican college websites. System 31: 247-258. 